\title{
A teoria da justiça de Schopenhauer
}

\author{
Flamarion Caldeira Ramos \\ Universidade Federal do ABC-São Paulo
}

\begin{abstract}
RESUMO
A teoria schopenhaueriana da justiça se estabelece de forma negativa: a noção de injustiça é primitiva e positiva, e a de justiça é secundária e negativa. A injustiça é a invasão no domínio onde se afirma a vontade do outro: uma ação injusta é aquela que consiste na destruição ou ferimento do corpo do outro, ou então na redução das forças desse corpo ao seu próprio serviço. O objetivo da legislação estatal é, assim, apenas evitar a injustiça e não realizar a justiça. O Estado é uma instituição protetora, necessária devido aos ataques múltiplos aos quais o homem é exposto e dos quais ele não pode se defender senão por uma aliança com os outros. Schopenhauer ainda critica a visão daqueles que consideram o Estado como o propósito máximo da existência humana e a condição da liberdade e da moralidade. Trata-se de uma concepção de Estado "ultramínimo" cuja base é um certo pessimismo antropológico, já que "a necessidade do Estado repousa, em última instância, na reconhecida injustiça do gênero humano, sem o que não se teria pensado jamais num Estado" (P II, § 123). O objetivo do presente artigo é investigar as bases e as consequências da teoria da justiça de Schopenhauer e ver como essa visão se sai diante do debate contemporâneo sobre a justiça.
\end{abstract}

Palavras-chave: Schopenhauer. Justiça. Direito. Estado.Vontade

\section{ABSTRACT}

For Schopenhauer the concept of injustice (Unrecht) is the original, while the opposite concept of right is the derivative and negative. Injustice is the quality of an individual's conduct in which he extends the affirmation of the will that appears in his own body so far that it becomes the denial of the will that appears in the bodies of other. The concept of right (Recht) contains merely the negation of wrong or injustice, and under it is subsumed every action which is not a denial of another's will for the stronger affirmation of one's own. The aim of the positive legislation is to avoid injustice and not to realize justice. The State is essentially a mere institution for protecting all from external attacks and individuals from attacks within its borders and Schopenhauer criticizes the view that represents the State as the highest purpose and the flower of human existence, and hence as the condition of freedom and morality. This is a conception of the ultra-minimum State which is based on an anthropological pessimism for "the necessity of the State rests ultimately on the acknowledged injustice and unfairness of the human race" (P II, § 123). We shall discuss Schopenhauer's negative doctrine of justice in relation to contemporary debate on justice.

Key-words: Schopenhauer. Justice. Right. State. Will

A ética de Schopenhauer é normalmente caracterizada como uma "ética da compaixão" enraizada numa metafísica da vontade. Como aspectos principais de sua filosofia moral são destacados, por um lado, a descrição pessimista dos sofrimentos do mundo e por outro o caráter irremediável dessa situação dada a impossibilidade de 
qualquer mudança significativa do mundo, esse último não sendo mais que mero espelho da vontade de viver, o que resulta então na teoria da negação da vontade de viver, única possibilidade de redenção. A teoria da justiça é vista apenas como a descrição do primeiro estágio da consciência moral rumo à supressão da vontade. Nesse artigo, porém, gostaria de apresentar a concepção schopenhaueriana da justiça à parte de sua metafísica da vontade e independente do movimento conceitual que, no quarto livro de $O$ Mundo como vontade e representação, a descreve como o primeiro momento do despertar da consciência moral. Desse ponto de vista, ressaltaremos as passagens em que a justiça é descrita não como algo secundário, mas pelo contrário, como uma virtude primordial, a saber, a "primeira e fundamental virtude cardeal" (Schopenhauer, 1995, p. 151). Descolada de sua metafísica dos costumes, embora não de sua ética em sentido estrito, a teoria da justiça de Schopenhauer poderá ser avaliada certamente como uma visão não apenas razoável, mas bastante atual diante do debate contemporâneo sobre a justiça. Por outro lado, quando do ponto de vista metafísico, a justiça enquanto virtude é relativizada, nomeadamente na teoria da "justiça eterna", Schopenhauer expressa a consciência dos limites de sua própria abordagem e, por consequência, também da abordagem meramente empírica da justiça. Dessa forma, eu gostaria de expor essas reflexões dividindo-as em 3 partes: Na primeira e mais substancial parte do texto, a teoria da justiça de Schopenhauer é exposta de maneira sistemática, por meio da leitura de seu principal texto sobre o tema, a saber, o $\S 62$ de $O$ mundo como vontade e representação, referindo-se também aos complementos que essa teoria recebeu em sua obra publicada. Em segundo lugar, comento brevemente a atualidade e a relevância do pensamento schopenhaueriano sobre a justiça; e, por fim, num terceiro momento, concluo brevemente comentando sua teoria da justiça eterna, vista aqui como reflexão sobre os limites de realização das aspirações da vontade humana.

Schopenhauer expõe o fundamental de sua teoria da justiça no $\S 62$ de sua obra principal, ao descrever a passagem da afirmação para a negação da vontade (§§ 60-68) ${ }^{1}$. A afirmação da vontade de viver no indivíduo pode conduzi-lo a negar a mesma vontade que se expressa no outro. É o egoísmo levado à sua mais extrema consequência

\footnotetext{
${ }^{1}$ De acordo com a indicação do próprio Schopenhauer (2005, p. 443), sua pura doutrina do direito expressa no $\S 62$ pode ser dividida em cinco partes: I - Explanação do sentido íntimo e próprio e da origem dos conceitos de injusto e justo, bem como sua aplicação e lugar na moral (1-2); II - Dedução do direito de propriedade (3); III - Dedução da validade moral dos contratos (4 - 5); IV - Explanação da origem e do fim do Estado e da relação deste fim com a moral, assim como da transferência apropriada da doutrina moral do direito, por inversão, para a legislação $(6$ - 14) e V - Dedução do direito penal (15 16). O último parágrafo tem como tarefa ainda mostrar a insuficiência do Estado e da política para garantir a satisfação da vontade (17).
} 
a fonte da injustiça. A teoria schopenhaueriana da justiça se estabelece então de forma negativa: a noção de algo injusto (Unrecht) é primitiva e positiva, e a de justiça é secundária e negativa. A injustiça é a invasão no domínio onde se afirma a vontade do outro: uma ação injusta é aquela que consiste na destruição ou ferimento do corpo do outro, ou então na redução das forças desse corpo ao seu próprio serviço; assim o injusto aumenta as forças ao seu serviço e ultrapassa essa soma de recursos que é seu próprio corpo, ele afirma a sua própria vontade para além dos seus próprios limites e o faz negando a vontade manifestada num corpo estranho. As ações justas são aquelas que não ultrapassam os limites traçados pela vontade do agente, limites estes que apaziguam seu egoísmo.

Segundo Schopenhauer, não se falaria nunca em direito se não houvesse injustiça, pois a definição do direito a contém: "a doutrina do direito é uma parte da moral que estabelece as ações que não se podem fazer se não se quer prejudicar, quer dizer cometer injustiça" (Schopenhauer, 1972, vol. IV, p. 218 e 1995, p. 142). Assim, enquanto parte da moral, a "doutrina pura do direito" (reine Rechtslehre) se relaciona apenas ao fazer e não ao sofrer, pois apenas o fazer é uma expressão da vontade, e é esta última somente que a moral considera. Tendo sempre a ação como objeto, a doutrina do direito consiste na "determinação exata do limite até onde um indivíduo pode ir na afirmação da vontade, já objetivada em seu próprio corpo, sem que se torne negação dessa vontade que aparece em outro indivíduo; assim, também conteria a determinação das ações que ultrapassam o mencionado limite, e que portanto, por ser injustas, podem ser defendidas sem injustiça”.(Schopenhauer, 1972, vol. II, p. 404 e 2005, p. 438). Só posso ultrapassar o limite do direito, que é a vontade alheia, para defender o meu direito de coação (Zwangsrecht), que consiste em constranger, pela oposição da força, toda vontade que queira negar a minha.

A legislação (Gesetzgebung), ao contrário, toma em consideração a doutrina moral do direito para usá-la no seu lado passivo, para considerar as mesmas ações que ninguém deve padecer para que nenhuma injustiça deva suceder-lhe. Contra estas ações o Estado cria as leis, o direito positivo. O objetivo deste é que ninguém sofra injustiça. "Em contrapartida, o objetivo da doutrina moral do direito é que ninguém faça injustiça” (Schopenhauer, 1995, p. 142).

Assim, segundo o autor, o direito e a injustiça são noções puras e simplesmente morais, têm significado apenas para quem tem em vista a ação humana considerada em si, e o seu valor íntimo, ou seja, "para os homens considerados enquanto homens, não 
enquanto cidadãos do Estado" ("für den Menschen als Menschen, nicht als Staatsbürger", Schopenhauer, 1972, vol. II, p. 403 e 2005, p. 437). Essa significação puramente moral das palavras "direito" e "justiça" subsiste mesmo no estado de natureza, na ausência de toda lei positiva; é ela que constitui a base e a substância de tudo o que se denomina direito natural, e que seria melhor denominado "direito moral", visto que aquilo que lhe é característico é não se estender àquilo que age sobre nós, à realidade exterior; seu domínio é o de nossa atividade interior, do conhecimento natural de nossa própria vontade, que nasce do exercício de nossa atividade, e que se chama consciência moral. Os conceitos de justo e injusto têm, neste estado, apenas valor de conceitos morais e relacionam-se simplesmente com a consciência que cada um possui da vontade que reside em si. Esse significado moral das ações é revelado na experiência interna, pois a prática da injustiça é acompanhada de uma "dor interior, a qual é simplesmente a consciência sentida de quem praticou a injustiça via força excessiva de afirmação da vontade presente nele mesmo até o grau de negação do fenômeno da vontade alheia" (Ibid, Idem). Esse sentimento é o remorso (Gewissensangst) que acusa a nossa iniquidade e nos anuncia aquele laço metafísico profundo que une os indivíduos uns aos outros. ${ }^{2}$

Para o filósofo, se deixamos de lado essa consideração puramente moral das ações humanas, ou se a negamos, caímos no erro comum a Hobbes e a Espinosa, erro que consistiria em negar que exista um direito para além do Estado, isto é, segundo Schopenhauer, confundir o direito com os meios de fazê-lo valer. (Cf. Schopenhauer, 1972, vol. III, p. 683, Capítulo 47 dos “Complementos”). Embora só possa haver garantia do direito no Estado, em si mesmo ele é independente dele, pois se o direito é violentado no estado de natureza ele não é, no entanto, jamais suprimido. Enquanto tal, porém, ele existe apenas na consciência, não vai além do indivíduo que o reconhece. Assim, a consciência não pode impedir que, no estado de natureza, a violência se estabeleça em vez do direito. No estado de natureza, depende de cada um e sempre não cometer injustiça, mas não depende em nenhum caso de cada um não sofrer injustiça, isso depende apenas da força exterior de cada um. Desse modo, ainda que por um lado, os conceitos de justo e injusto tenham valor independentemente da legislação estatal e não sejam convencionais, por outro, eles valem apenas como meros conceitos morais

\footnotetext{
${ }^{2}$ CF. Ibid. Idem. Esta dor surge na consciência de quem comete injustiça quando ele reconhece "também que ele, como fenômeno é diferente da vítima da injustiça, mas em si mesmo é idêntico." Sobre este sentimento, vale para a nossa análise aquilo que aqui diz Schopenhauer: "A continuação da explicação desse significado íntimo do remorso, só pode seguir-se mais a frente". (Ibid, Idem).
} 
(bloßalsmoralischeBegriffe) e relacionam-se com o autoconhecimento que cada um possui de si. (Cf. Schopenhauer, 1972, vol. II, p. 403). Dessa forma, o Estado será concebido apenas como uma instituição protetora, necessária devido aos ataques múltiplos aos quais o homem é exposto e dos quais ele não pode se defender senão por uma aliança com os outros ${ }^{3}$.

Graças à razão, os homens descobrem um meio de diminuir as dores inseparáveis da vida humana das quais o egoísmo é a causa, até quase suprimi-las na medida do possível. Este meio é um sacrifício comum, compensado por sua vez pelas vantagens comuns que se obtêm com ele. O egoísmo orientado pela razão descobre esse meio, e o aperfeiçoa na medida do possível: é enfim, o contrato social, a lei. Schopenhauer expõe então sua teoria do contrato social, como o modo universal em que surge o Estado, como uma maneira natural que o homem, com o desenvolvimento de sua razão, se relaciona com os outros homens. Para o filósofo, a razão, enquanto instrumento da Vontade, se eleva do ponto de vista do indivíduo até a perspectiva da universalidade e percebe que o prazer produzido num dos indivíduos pelo ato injusto é destruído por um sofrimento maior em proporção que se produz no outro. A razão "reconhece, a partir daí, que tanto para diminuir o sofrimento espalhado em toda parte quanto para reparti-lo da maneira mais equânime possível, o melhor e único meio é poupar a todos a dor relacionada ao sofrimento da injustiça, fazendo-lhes renunciar ao gozo obtido com sua prática. Esse meio, facilmente divisado e gradualmente aperfeiçoado pelo egoísmo, o qual, usando a faculdade de razão, procedeu metodicamente e abandonou o seu ponto de vista unilateral, é o contrato de Estado ou a lei" (Schopenhauer, 1972, vol. II, p. 405 e 2005, p. 439).

Schopenhauer não concebe qualquer outra origem possível para o Estado. Independentemente das condições pelas quais esse contrato social é feito, o que faz aparecer o Estado é sempre o contrato consentido por todos. O Estado será considerado mais ou menos imperfeito conforme este contrato é mais ou menos alterado por uma mistura de elementos anárquicos ou despóticos. Para fundar um Estado perfeito, segundo o autor, seria preciso começar por fazer seres a quem a natureza permitisse sacrificar totalmente o seu bem particular ao bem público. ${ }^{4}$

\footnotetext{
3 A partir dessa definição da finalidade do Estado, Schopenhauer deduz o direito de punir (Strafrecht). Segundo Mario Cattaneo (1986, p. 96) é ao definir o Estado como instituição coercitiva e não como uma instituição educativa ou "melhoradora" que Schopenhauer se aproxima de Hobbes.

${ }^{4}$ A partir desse raciocínio, Schopenhauer argumenta em favor de sua preferência em relação ao regime monárquico. Se o regime misto, inventado para escapar respectivamente, da anarquia e do despotismo,
} 
O Estado nasce assim do egoísmo esclarecido dos indivíduos, que se elevam do ponto de vista individual para o ponto de vista universal, sendo o resultado do egoísmo comum a todos ${ }^{5}$. Não é, contudo, a satisfação do egoísmo que o Estado tem em vista, mas apenas as consequências funestas do mesmo, visto que, graças à multiplicidade dos indivíduos, todos egoístas, cada um está exposto a sofrer suas consequências. Como está baseada na teoria pura do direito, a política serve-se dela para seus próprios fins. $\mathrm{O}$ direito moral encontra-se na base da legislação jurídica exatamente como a matemática pura está na base das matemáticas aplicadas. Portanto, "somente se a legislação positiva for determinada essencialmente a partir da pura doutrina do direito, e a razão para cada uma de suas leis puder ser indicada por ela, somente então poderá a legislação constituir um verdadeiro direito positivo, e o Estado uma associação legal e justa, um Estado no sentido próprio do termo, uma instituição admissível moralmente, não imoralmente. Caso contrário, a legislação positiva seria apenas o estabelecimento de uma injustiça positiva, apenas uma injustiça imposta e publicamente admitida". (Schopenhauer, 1972. vol. II, p. 409; 2005, p. 443) $)^{6}$. Dessa forma, ainda que o Estado não se constitua como uma instituição voltada para a produção da virtude, ele se apresenta, quando é legitimamente instituído, como uma instituição ao menos baseada na justiça.

Apesar de estar fundado na moral, o Estado não pode transformar a vida em comum num paraíso moral. É certo que no Estado ideal cada um persegue o bem de todos, porque cada um sabe que seu próprio bem está envolvido naquele. Se ele alcança inteiramente seu objetivo, ele produzirá certamente a aparência de uma comunidade em que a moralidade perfeita reinasse sobre todas as ações. Mas há uma diferença fundamental entre a moralidade e o Estado que corresponde às finalidades distintas que perseguem. Enquanto a ética trata apenas das ações, e com relação a estas, a intenção com que ela foi realizada, a teoria do Estado tem em vista apenas a vítima da injustiça.

\footnotetext{
acaba tendendo para o reino das facções, na monarquia o inconveniente da separação entre o bem público e o bem particular apresenta-se menos problemática: "nos aproximamos do alvo onde existe uma família cuja fortuna está inseparavelmente unida à do país; deste modo, ela não pode, pelo menos nos negócios importantes, procurar o seu bem fora do bem público. Daí vem a força e a superioridade da monarquia hereditária". Ibid., p. 406.

${ }^{5}$ Por enxergar no imperativo categórico de Kant apenas um princípio de reciprocidade, e portanto baseado no egoísmo, Schopenhauer o considera "excelente como base da doutrina do Estado" (1980, p. 174) ainda que imprestável para fundar a ética. Rawls critica a interpretação de Schopenhauer e tenta provar que a mesma objeção não se aplicaria a sua teoria da justiça (Cf. Rawls, 2000, PP. 150-2).

${ }^{6}$ Deve-se notar aqui que quando Schopenhauer fala em teoria pura do direito (reine Rechtslehre) o significado disso em nada se compara à "teoria pura do direito" de Kelsen. Para este último, a pureza metodológica serve justamente para pensar o direito como uma ciência pura sem interferência do conceito ético e político de justiça. Para Schopenhauer, se trata exatamente do contrário: a teoria pura do direito é "um capítulo da moral" na qual ela se fundamenta.
} 
Quanto ao autor, não se importaria com ele se ele não fosse o correlativo forçado da vítima. Para ela, o ato injusto é apenas o adversário contra o qual ela emprega os seus esforços.

O Estado não tem, portanto, a tola pretensão de destruir a inclinação das pessoas para a injustiça, nem os pensamentos malignos, ele limita-se a colocar, ao lado de cada tentação possível, capaz de nos arrastar para a injustiça, um motivo ainda mais forte capaz de nos desviar, o castigo e a pena. É assim que a noção de injustiça e a da negação do direito que o injusto encerra, noção que é originalmente de ordem moral, torna-se jurídica. A noção moral do direito é convertida pelo jurista e orientada para o lado passivo. Assim, Schopenhauer compara o jurista e o moralista, e afirma que assim como o historiador é um profeta ao contrário, o jurista seria um moralista ao contrário. A teoria pura do direito seria, então, a moral "ao contrário". (Schopenhauer, 1972, vol. II, p. 407). Essa seria a origem do engano de se pensar que o Estado é um meio de nos elevar à moralidade, que nasce duma aspiração à virtude. $\mathrm{O}$ erro consiste em pensar que a liberdade possa ser modificada por uma intervenção social. Mas ela está para além das instituições humanas, fora do mundo dos fenômenos. "Por meio de motivos, diz o autor, pode-se forçar a legalidade, não a moralidade. Pode-se transformar a ação, mas não o próprio querer, ao qual somente pertence o valor moral. Não se pode mudar o alvo para o qual a vontade se esforça, mas apenas o caminho que ela trilha para atingi-lo". (Schopenhauer, 1972, vol. IV, p. 255; 1995, p. 189). O Estado então só nos oferece uma aparência de moralidade: por sua própria natureza ele não pode proibir uma ação injusta que não corresponda a nenhuma injustiça sofrida; ele não pode impor a prática da caridade, mas somente a proibição da prática da injustiça. Ao estabelecer esse divórcio entre teoria da virtude e teoria do direito, Schopenhauer se opõe à doutrina do direito de Kant, e critica a afirmação de Kant de que haveria uma obrigação moral para a instituição do Estado. ${ }^{7}$

Com relação especificamente à doutrina do direito de Kant, Schopenhauer faz duas observações principais: em primeiro lugar, critica a ideia de que não haveria um direito de propriedade fora do estado civil; em segundo lugar, critica, a nosso ver erroneamente, a tentativa kantiana de distinguir direito e ética. Quanto ao primeiro

\footnotetext{
7 “... A doutrina do direito de Kant, o qual, do imperativo categórico, deduz falsamente a fundação do Estado como um dever moral..." (Schopenhauer, 1972, § 62, vol. II, p. 407; 2005, p. 441). "Do direito privado no estado de natureza provém o postulado do direito público: tu deves, em virtude da relação de uma coexistência inevitável com todos os outros, sair deste estado para entrar no estado jurídico, ou seja, naquele de justiça distributiva". Kant, 1968,Ak. VI, § 42, 307.
} 
ponto, Schopenhauer afirma contra $\mathrm{Kant}^{8}$ a subsistência do direito de propriedade mesmo no estado de natureza: “em conformidade com a nossa dedução recém-feita, há sim propriedade no estado de natureza, lastreada em direito perfeitamente natural, isto é, moral, o qual não pode ser violado sem injustiça, podendo pois ser defendido sem injustiça" (Schopenhauer, 1972, vol. II, p. 410; 2005, p. 444) ${ }^{9}$. Quanto ao segundo ponto, Schopenhauer afirma que o conceito de direito deve ou ser inteiramente ético, ou inteiramente físico (e, portanto, arbitrário, fundado apenas na lei positiva), e não um híbrido dos dois como seria a determinação desse conceito em Kant: "Consequentemente, em Kant, o conceito de direito oscila entre o céu e a terra e não tem nenhum chão em que possa pisar: para mim ele pertence à ética” (Schopenhauer, 1980, p. 177). A crítica de Schopenhauer com respeito a esse segundo ponto, no entanto, falha ao não observar que em Kant também o direito, tanto como a ética, pertence ao domínio da filosofia prática, ao mundo do dever e da liberdade.

A constituição da filosofia prática em Kant se dá em dois caminhos: um o da liberdade externa, que tem a ver com a limitação recíproca do arbítrio, para que a liberdade de cada um possa coexistir com a liberdade de todos os outros segundo uma lei universal (sendo essa a própria formulação do imperativo categórico do direito - Cf. Kant, 1968, vol. VI, p. 230); o outro o da liberdade interna, enquanto capacidade que tem o indivíduo de dar a si mesmo fins propostos por sua própria razão. A dupla face da liberdade (interna e externa) se apresenta como o princípio da distinção da ética e do direito. A partir disso, temos então a divisão fundamental da Metafísica dos Costumes: o direito trata da justiça e a ética da virtude. $O$ direito trata da coexistência da liberdade de cada um com a de todos os outros; a ética trata da liberdade que cada um dá a si mesmo.

Em Schopenhauer, da mesma forma, o direito diz respeito à condição externa da moral, à "liberdade política" ou "física", e não à determinação da virtude. Por essa razão, “apenas o negativo, que é o direito, poder ser imposto, não o positivo, o qual se entendeu sob a rubrica de deveres de caridade ou deveres imperfeitos" (Schopenhauer, 1972, vol. II, p. 409; 2005, p. 443). Assim, Schopenhauer expressa uma divisão entre

\footnotetext{
${ }^{8}$ Para Kant, somente num estado jurídico, num estado civil em que haja um poder público, pode-se ter algo exterior como seu: "uma posse na espera e preparação de um tal estado, que só pode ser fundado numa lei da vontade comum, que assim está de acordo com a possibilidade da última, é uma posse provisória e jurídica, em compensação aquela que se encontra num tal estado seria uma posse peremptória" (Kant, 1968,Ak. VI, § 9, p. 257).

${ }^{9}$ Não somente com respeito à defesa do direito natural de propriedade, mas também por conta de sua rejeição do caráter meramente convencional das noções de justo e injusto, Schopenhauer parece mais próximo do pensamento de Locke do que de Hobbes, com quem é constantemente comparado. Todavia, o autor nunca menciona, em sua obra publicada, as obras políticas de Locke.
} 
ética e direito bem próxima daquela que Kant já defendera; nesse sentido, sua posição não se distancia da teoria tradicional do direito natural. ${ }^{10}$

Assim, direito e ética têm fontes distintas. Enquanto a noção de justiça do ponto de vista da doutrina do direito, tem sua justificação no egoísmo e na necessidade de conciliação pragmática entre os indivíduos, a noção de justiça do ponto de vista ético se fundamenta na compaixão, sentimento natural que por sua vez baseia-se na indiferenciação metafísica de todos os seres enquanto manifestação de uma mesma vontade. Nesse sentido, Schopenhauer sugere uma diferença entre a justiça voluntária, por um lado, enquanto manifestação de uma virtude moral e a mais elementar entre elas, e por outro, a justiça que o indivíduo é forçado a observar por conta do contrato de Estado e da lei positiva.

A partir dessa teoria do Estado, Schopenhauer critica os filósofos alemães contemporâneos acusando-os de terem deturpado inteiramente o sentido da teoria do direito natural. Com isso, segundo Schopenhauer, as claras e simples relações da vida teriam sido tornadas incompreensíveis enquanto que as coisas nelas mesmas seriam simples e apreensíveis - simplex sigillumveri, frase constantemente repetida pelo autor. Aqui, a crítica à verborragia filosófica se junta à defesa de uma visão liberal do Estado cuja base é um certo pessimismo antropológico, ou ao menos o pressuposto de que, no geral, o homem jamais supera seu egoísmo.

\begin{abstract}
Em minha obra principal (vol. 2, capítulo 47) mostrei que o Estado é essencialmente uma mera instituição de proteção de todos contra ataques externos e dos indivíduos entre si. Disso se segue que a necessidade do Estado repousa, em última instância, na reconhecida injustiça do gênero humano, sem o que não se teria pensado em nenhum Estado, pois ninguém temeria prejuízo a seu direito e uma mera reunião contra os ataques de animais selvagens ou dos elementos naturais teria uma fraca semelhança com um Estado. Desse ponto de vista vê-se claramente a trivialidade e a platitude dos filosofastros que, em discursos pomposos, apresentam o Estado como o
\end{abstract}

\footnotetext{
${ }^{10}$ Cf. Cattaneo, Mario A. "Schopenhauers Kritik der Kantischen Rechtslehre" In: Schop. Jarbuch, n 69, 1988, p. 405: "De fato, Schopenhauer chega, pela sua ênfase no significado da doutrina do direito enquanto interdição da injustiça, para evitar o sofrimento, exatamente lá onde Kant já havia, por um outro caminho, chegado. Embora critique a opinião de Kant de que o Estado e o direito constituem as condições para uma conduta moral justa e livre, Schopenhauer concorda com ele na distinção entre o direito, que é coercitivo, e a moral, que não pode ser objeto de coerção; isso significa que ambos, Schopenhauer $e$ Kant, são representantes do liberalismo clássico e defensores do estado de direito, e que ambos se distanciam da posição de Hegel, que considera o Estado como a fonte da moralidade (Moralität) ou como "substância ética",.
} 
fim supremo e a flor da existência humana, com o que oferecem uma apoteose do filisteísmo (Schopenhauer, 1972, vol. VI, p. 265) ${ }^{11}$.

Tendo exposto o essencial da teoria da justiça de Schopenhauer podemos fazer uma breve comparação entre sua abordagem e aquela que tem sido objeto de importantes discussões na filosofia política contemporânea, a saber, a teoria da justiça como equidade de John Rawls. Com a publicação, em 1971, de Uma Teoria da Justiça John Rawls (1921-2002) reatualizou a questão da justiça nas reflexões da filosofia política contemporânea. Ao retomar a tradição do constitucionalismo democrático, que encontra uma de suas raízes na doutrina do contrato social (Locke, Rousseau e Kant), Rawls reacende a discussão sobre o ideal de uma sociedade justa de cidadãos livres e iguais, deslocando a reflexão sobre os temas clássicos da filosofia política moderna (análise da natureza do poder, da origem e legitimidade do Estado e da lei, o conceito de soberania) para a questão de como realizar efetivamente os ideais de liberdade e igualdade da cidadania democrática. Com a crise do liberalismo de bem-estar social e do socialismo real a teoria da justiça de Rawls deu novo ânimo para as reflexões de filosofia política normativa e ao debate sobre os fundamentos de uma sociedade justa. Mas a centralidade da obra de Rawls está no fato de que sua obra está no centro do debate entre duas posições opostas sobre o bem e a justiça: o conceito de Justiça pode ser entendido ou a partir de reflexões sobre o indivíduo, ou de considerações sobre a sociedade. Isto é, a Justiça pode se expressar na preservação da liberdade dos indivíduos, ou na construção das condições de uma vida social bem sucedida. É nesse sentido que surge o debate entre liberais (John Rawls, Robert Nozick, R. Dworkin) e comunitaristas (M. Walzer, M. Sandel, A. MacIntyre). Enquanto os liberais priorizam o justo sobre o bem, entendendo que o indivíduo deve estar protegido por uma série de direitos prévios, para os comunitaristas não bastaria a referência a princípios universalistas abstratos que garantiriam a justiça, pois além disso seria preciso se remeter a uma concepção do bem sem o qual o raciocínio moral e político ficaria indeterminado e não forneceria um guia para o que devemos fazer. A partir disso, o desafio do pensamento liberal tem sido o de oferecer uma resposta aos críticos que vêm na tradição do liberalismo apenas uma postura de manutenção do status quo derivada de

\footnotetext{
${ }^{11}$ Capítulo 9 do segundo volume dos Parerga e Paralipomena, Sobre a doutrina do direito e a política, $\S$ 123.
} 
uma falsa opção ontológica, a saber, o atomismo, já que tomariam o indivíduo como o ponto de partida da reflexão política.

Seria possível mostrar que a teoria da justiça de Schopenhauer, entendendo-a antes como uma teoria moral e não estritamente metafísica ${ }^{12}$, corresponde àquilo que tem sido caracterizado como a principal característica do liberalismo contemporâneo: a defesa de uma concepção negativa de liberdade articulada pela prioridade do justo sobre o bem. Daí se pode entender por que a justiça é descrita como a primeira e fundamental virtude cardeal: por que ela garante um direito inviolável ao indivíduo de respeito ao seu espaço privado de afirmação de si. O objetivo da legislação estatal é, assim, apenas evitar a injustiça e não realizar a justiça. O Estado é uma instituição protetora, necessária devido aos ataques múltiplos aos quais o homem é exposto e dos quais ele não pode se defender senão aliando-se com os outros. Mas com isso o Estado deixa de se preocupar com o bem comum, atuando apenas como aquela instância que garante a proteção dos proprietários. Schopenhauer ainda critica a visão daqueles que veem na realização do Estado o propósito máximo da existência humana e a condição da liberdade e da moralidade. É verdade que aqui Schopenhauer está longe de defender algum tipo de liberalismo igualitário já que não desenvolve uma noção positiva de justiça e por isso sua concepção estaria mais próxima do libertarianismo de Nozick e do assim chamado liberalismo hobbesiano de autores como Harsanyi e Gauthier. Por outro lado, sua concepção minimalista de Estado o afasta do utilitarismo.

Por fim, cabe reconhecer os limites que o próprio Schopenhauer estabeleceu para a justiça empírica. Do ponto de vista metafísico, assumida a unidade da Vontade e o caráter meramente ilusório dos indivíduos, o sofrimento do mundo não é senão resultado da própria tragicomédia da vontade, já que ela "encena a grande tragicomédia à própria custa" (Schopenhauer, 1972, vol. II, p. 423; 2005, p. 457). Sendo toda multiplicidade mera aparência então também a responsabilização individual é ilusória: só há uma única vontade que carrega em si tanto o malumculpae como o malumpoenae. A unidade do carrasco e da vítima é o resultado da metafísica que apaga a distinção entre os seres. Essa chamada "justiça eterna" (ewigeGerechtigkeit) não depende do tempo e está para além das instituições humanas, ela é "aquela que rege não o Estado,

\footnotetext{
${ }^{12}$ Seria difícil tentar abstrair a teoria da justiça de Schopenhauer de sua metafísica da vontade já que a própria definição de justiça (como negação do injusto) contém uma referência à vontade compreendida metafisicamente como coisa-em-si. No entanto, no ensaio Sobre o fundamento da Moral, a definição oferecida, de acordo com a limitação imposta pelo concurso para o qual ele foi escrito, prescinde do conceito de vontade: "a injustiça ou o injusto consistem, pois, sempre na ofensa de um outro" (Schopenhauer, 1995, p. 139).
} 
mas o mundo, sendo independente das instituições humanas, não submetida ao acaso, ao engano, sem ser incerta, oscilante, sem errar, mas infalível, firme e certa. - O conceito de retaliação já implica o tempo: eis por que a justiça eterna não pode ser retaliadora, portanto não admite dilação e atraso, nem compensa pelo tempo o ato maléfico com a consequência maléfica, e assim necessitaria do tempo para subsistir. A punição na justiça eterna tem de ser tão ligada à injúria que ambas se tornam unas" (Schopenhauer, 1972, vol. II, p. 414; 2005, p. 448).

Assim como a ideia da responsabilidade moral deve se referir ao ser e não às ações das quais ele decorre, da mesma forma a vontade, enquanto se manifesta no mundo dos fenômenos e constitui sua essência, deve ser vista como a responsável por tudo aquilo que nele acontece. Se o mundo é assim é porque a vontade assim o quis. "O tribunal do mundo é o próprio mundo"(Ibid, p. 415). Para compreender essa justiça eterna seria preciso, no entanto, abandonar o fio condutor do princípio de razão, desligar-se do modo de conhecimento que se liga apenas ao particular, elevar-se até a visão das ideias, ver além do princípio de individuação, e convencer-se de que às realidades consideradas em si mesmas já não podem aplicar-se as formas do fenômeno. Sendo assim, mesmo entre o carrasco e a vítima, entre aquele que faz o mal e o que sofre, não há nenhuma diferença essencial: a mesma vontade se apresenta em ambos. $\mathrm{O}$ significado moral do remorso reside justamente na irrupção inconsciente dessa verdade aqui meramente sentida.

Se essa teoria é mais do que uma fantasia mistificadora, a consequência se impõe: se o mundo é simplesmente tal como é e não pode ser objeto de nenhuma transformação pelas instituições humanas, o que resta é simplesmente querer ou não este mundo - tertium non datur. Somente a negação completa da vontade poderia redimir o mundo e livrá-lo de suas dores - embora com isso, poderíamos dizer, se suprimiria também toda possibilidade de realizar qualquer ideal de bem - esse último certamente foi preterido em nome de uma exigência inconcebível de justiça. 


\section{Referências Bibliográficas}

Cardoso, Renato César. A ideia de justiça em Schopenhauer. Belo Horizonte: Argvmentvm, 2008.

Cattaneo, Mario. "Das Problem des Strafrechts im Denken Schopenhauers", In: Schopenhauer Jahrbuch, $\mathrm{n}^{\mathrm{0}}$ 67, 1986, pp. 95-112.

Schopenhauer Jahrbuch, ${ }^{\circ}$ 69, 1988, pp. 399-407.

"Schopenhauers Kritik der Kantischen Rechtslehre" In:

Gargarella, Roberto. As teorias da justiça depois de Rawls. Um breve manual de filosofia política. São Paulo: WMF Martins Fontes, 2008.

Giacoia Jr.,Oswaldo. "A mentira e as luzes: aspectos da querela a respeito de um presumível direito de mentir". In: Puente, Fernando Rey. Os filósofos e a mentira. Belo Horizonte: Editora UFMG, 2002.

Godart-van der Kroon, Annette. "Schopenhauer's Theory of Justice and its Implication to Natural Law”.In: Schopenhauer Jahrbuch, n ${ }^{\circ}$ 84, 2003, pp. 121-145.

Hamlyn, D.W. "Eternal Justice”. In: Schopenhauer Jahrbuch, no 69, 1988, pp. 281 288.

KAnt, I. Metaphysische Anfangsgründe der Rechtslehre. Edição da Academia de Ciências de Berlim (Deutsche Akademie der Wissenschaften). Berlin: Walter de Gruyter, 1968, vol. 6.

Kelsen, H. Teoria pura do direito. São Paulo, Martins Fontes, 2006.

Küpper, Georg. "Der Begriff des Unrechts bei Schopenhauer". In: Schopenhauer

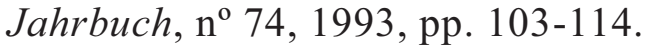

Rawls, J. O Liberalismo Político. Tradução de Dinah de Abreu Azevedo. São Paulo: Ática, 2000.

Schopenhauer, Arthur. Sämtliche Werke. Editadas e comentadas criticamente por Arthur Hübscher, Wiesbaden, F. A. Brockhaus, 1972, 7 vols.

- Crítica da Filosofia Kantiana. Tradução de Maria Lúcia

Cacciola, In: Coleção “Os Pensadores”, São Paulo, Abril Cultural, $2^{\text {a }}$ ed., 1980.

.Sobre o Fundamento da Moral. Tradução de Maria Lúcia Cacciola, São Paulo, Martins Fontes, 1995.

.O Mundo como Vontade e como Representação. Tradução de Jair Barboza, São Paulo: Unesp, 2005. 